LSP International Journal, Vol. 7, Issue 2, 2020, 37-54

(C) Universiti Teknologi Malaysia

E-ISSN 2601-002X

DOI: https://doi.org/10.11113/lspi.v7.16342

\title{
Facing Up to the Challenges in Teaching and Learning English in Polytechnics
}

\author{
Shahiza Ahmad Zainuddin \\ Jabatan Pendidikan Politeknik, Putra Jaya, Malaysia \\ Yusri Kamin* \\ Faculty of Education, Universiti Teknologi Malaysia, 81310 UTM Johor Bahru, Johor, Malaysia \\ Submitted: 17/09/2020. Revised edition: 26/11/2020. Accepted: 26/11/2020. Published online: 30/11/2020
}

\begin{abstract}
The competency of English among future graduates has consistently been discussed and has become a national concern. The impact of not having competency in English contributes to the hindrance of communication. Thus, English language becomes a major factor graduates are not able to secure suitable employment or to perform at work. The Technical and Vocational Education Training providers such as polytechnics share the same concern as the other institutions. English courses are taught as compulsory course for all students and students are given opportunities to practise the language through co-curricular activities. Communicative English is offered in three semesters, to support the core subjects and complement the technical subjects. In leading towards development and preparing graduates to meet the needs of the future, it is pertinent to ensure that the outcome of English courses in polytechnics is to produce graduates with adequate language competency and ready for work. This chapter reveals the challenges faced by English and content lecturers based on teaching English in polytechnics, teaching the discipline content in English and the collaboration between both subject lecturers. Qualitative data is gathered based on interviews with the lecturers to discover the perception of lecturers from language and content disciplines. The challenges in teaching and learning English are analysed and recommendations for improvement are beneficial to be used as interventions to improve the teaching and learning of English in polytechnics.
\end{abstract}

Keywords: TESL, challenges, teaching \& learning, TVET, polytechnics

\subsection{INTRODUCTION}

Technical and Vocational Training (TVET) in Malaysia was initiated to alleviate poverty through skilled education and training, but today it helps to produce a skilled workforce for the nation. Nevertheless, the perception of technical and vocational education as second class in contrast to universities means it is seen as less attractive to students and public. The perception of TVET as the education system for those who are not qualified to enrol for university education contributes to a lack of public interest (Tilak, 2002). This perception contributes to a lack of student enrolment in technical and vocational institutions, which translates to a decrease of skilled workers in industries.

*Correspondence to: Yusri Kamin (email: p-yusri@utm.my) 
This misconception of TVET is noticed by the government and the then Prime Minister of Malaysia, himself has highlighted the need to shift the perception of technical and vocational education and the pressing need to transform the education system and make it more attractive. He stressed the image of TVET as a preferred choice for students in other developed countries, as compared to the situation in Malaysia (Mohd Najib, 2010).

Technical and vocational education in polytechnics aims to produce graduates who can contribute their expertise and competency for the country. The Department of Polytechnic Education (DPE) is determined to transform and rebrand polytechnics as a preferred higher education institution that offers technical and vocational. Knowing that the fields of science and technology is rapidly evolving, the programmes running at this institution need to be at par with programmes offered at other higher education institutions.

However, in moving towards development, the DPE needs to overcome challenges that might hinder polytechnics from achieving its objectives. One of the challenges is producing technically skilled graduates through a reputable education system that is delivered by highly qualified and competent teaching staff. Higher education institutions in Malaysia are competing to produce graduates with qualities that meet the needs of various stakeholders. Even though it is undeniable that there are other factors that may influence graduates' performance such as their social background, the DPE needs to ensure that their own institutions, the polytechnics, provide good education and training for the students. Thus, one of the ways to ensure the success of the polytechnics is through the workforce.

The strength of the DPE is the workforce, the academic staff. Hence, building up their competencies and maximising their expertise should enhance the quality of polytechnic graduates. It is expected that the technical lecturers should accept the fact that they need to acquire competency in both general and professional areas. General competency such as in English language helps the development of competencies in technical and professional areas (Wan and Mohammed, 2010). In their study conducted with polytechnic lecturers these writers found that the lecturers perceived both competencies as important, and it is vital to prepare relevant professional development programmes that are tailored to their needs. This chapter explores challenges faced in teaching and learning English in Malaysian Polytechnics.

\subsection{LANGUAGE SETTING IN MALAYSIAN POLYTECHNICS}

The Department of Polytechnic Education (DPE) as one of the providers for technical and vocational education is motivated to produce graduates who fit the market needs. It is crucial to ensure that the graduates of polytechnics are highly skilled and employable (DPE, 2011). The collaborative effort between higher learning institutions and industries is encouraged and ranks high in the DPE's priority list (DPE, 2011). One of the strategies to improve the quality of graduates of polytechnics is through their English skills. 
English language at polytechnics has advanced and is used not only during English subject but in teaching content subjects. The DPE believes that integrating English in teaching content would give advantages to the students. Starting 2008, it is made compulsory to use English in teaching and learning content subjects in all polytechnics in Malaysia. The Ministry of Education reverted the policy of using English in teaching Science and Mathematics in schools but higher education institutions such as polytechnics has continued using English as the medium of instruction. The reasons are to encourage the use of English language as a medium of communication, familiarise students with the technical concepts and increase the pace at which the students work, as minimal translations will be required for reading materials. Therefore, English is not only taught as a subject, but it is used as a medium of communication in teaching technical subjects.

In the Malaysian context, the focus on bilingual skills as a requirement for employment places extra demands on students and staff. The students and the staff realise these are not being met through regular language classes, nor by collaboration between language and content teachers. The content lecturers attempt in various ways to adapt and provide solutions in their individual efforts, but the perceptions are that outcomes are still not adequate. Bilingualism in polytechnics might not be clearly gazetted by the DPE but it is associated through the language used in the syllabus and test papers and recently through the department's circular (DPE, 2012). English in polytechnics allows the students to communicate more as compared to focusing on the use of language for specific purposes. The decision to adopt Communicative English is to ensure that the graduates of polytechnics are able to communicate competently in any situation and with people at their workplaces.

\subsection{ROLES OF THE ACADEMIC STAFF}

Academic staff is trusted to play an important role in achieving the aims listed in the Polytechnic Transformation Plan (PTP). Langford (1978) as cited in (Yee and Liew, 2011) indicated the strong linkage between teaching and education. The quality of relationship between students and lecturers is crucial to ensure effective learning (Naidoo and Jamieson, 2005). The development of academic staff has been noted by the DPE and aims to increase the percentage of PhD and Masters holders as one of the initiatives taken to upgrade professional qualifications among its workforce. This initiative is not only for academic staff at universities but polytechnics and community colleges too. Lecturers who are involved greatly in influencing students' learning, need assistance and support to face challenges in achieving the aims inspired in the PTP.

Previous studies on lecturers' workload showed polytechnic lecturers are positive about their duties to teach the students and placed teaching and learning at the highest rank (Mohd and Mohd, 2010; Yee and Liew, 2011). They agree with the priority to establish good and effective teaching and learning to the students but as academic staff at polytechnics, they cannot avoid getting extra jobs, which are not really related to their expertise. Lecturers are expected to be able to make sure both their teaching jobs and other administration jobs are successfully carried out. These ad hoc duties are usually assigned to lecturers by the top-level management at the polytechnics. In their position as 
staff, it is their job to receive and respond to direction from the top level. Mohd Ali and Mohd Jasmi (2010) also discovered lecturers are given ambiguous duties which may detract them from their core duty, which is teaching. Furthermore, they claimed they gain better respect and acknowledgement for successfully completed administrative jobs as compared to their teaching jobs (p.531).

As academic staff, lecturers have to play their role in producing quality graduates who are competent in their core subjects, desirable to the industries and proficient in English. In order to uplift polytechnics' image as an established higher learning institution, teaching staff should know and embrace the vision of their head of department. Without this knowledge, the DPE's well-inspired plans may not be realised. Lecturers should be aware of the needs of their students and expectations of ministries and industries. The DPE has acknowledged the necessity to train its staff. Therefore, professional development programmes at polytechnics are encouraged and a pre-requisite for promotion.

One of the programmes includes preparing the lecturers to teach technical subjects in English. The pressing demands from industries to improve students' English competency contribute to the DPE's decision to shift the language of instruction from Bahasa Melayu (Malay Language) to English. Employers in Malaysia are concerned when many Malaysians lack employability skills and most employers cited poor command of English as a reason for not hiring (Graduates unemployable due to poor English, 2010). In relation to this, the Malaysian government through the Ministry of Education is persistent in upgrading the TVET qualification through many plans. Providing instruction in skills and promoting the power of the mind should remain the main teaching purposes, however, in carrying out this role, higher education has to meet the needs of the economy (for highly skilled manpower) as well as those of the individuals (Bennet, Dunne, and Carre, 2000, p. 4). It is necessary to cultivate close rapport between the DPE; industries and students, in order to produce graduates who are knowledgeable, skilful and employable. By accepting English as the language of science, technology and business, the DPE has shown confidence that using English as the medium of instruction in teaching technical subjects will bring advantages to the students. The situation becomes more challenging when potential students need to use English for their teaching and learning at polytechnics when they have been using Malay Language as the medium of instruction in schools.

English has evolved as it is also used in teaching other technical subjects (DPE, 2012). The language shift may affect different groups of individuals including the lecturers and students at polytechnic. Academics are the group who are the main implementers of plans inspired by top management with students as the recipients. According to Gill (2005), in the Malaysian context, the government and education sectors must not be examined separately as every move for the nation requires approval from the government. Therefore, any strategy or plan is inter-related and does not work on its own. Each ministry must play its role in agreed implementations and since it is based on a top-down approach, lecturers at polytechnics are trusted to successfully run the programmes planned by the top management.

Lecturers are the closest to the student-client group, so, they play a huge role in implementing plans prepared by the DPE. The lecturers become the link between the top management and the students. Thus, developing the internal workforce at polytechnics is crucial in achieving any required missions. However, in gearing up towards becoming the preferred polytechnic, the DPE realizes the 
obstacles it has to encounter. The lecturers, themselves, are not machines or empty cans, which merely act as recipients. They are unique in their own way and have their own set of needs and expectations. In relation to the language shift, DPE needs to prepare many professional development programmes for staff to ensure effective implementation.

English has evolved at polytechnics as a subject learned and as the medium of instruction in teaching technical subjects. Even though English is the second language in Malaysia and students enter polytechnics with some language competency level, implementing the language shift may be challenging not only for the students but for the lecturers, too. Technical lecturers who have been teaching the content subject in Malay may encounter problems in delivering and conducting their classes. English lecturers have to face their own set of problems. They may still be teaching English but when more English is being used at polytechnics, as the medium of instruction for teaching other technical subjects, the English lecturers may need to assist technical lecturers to enhance their English proficiency. Students who have been using Malay Language in learning all subjects in schools may suffer the most.

\subsection{CHALLENGES FACED BY THE LECTURERS}

The main challenge is the need to handle assumptions placed on the English subjects and the lecturers. The needs of English increased when the DPE encouraged the use of the language in teaching all technical subjects. In polytechnics, English was taught for specific purposes (ESP) but changed to Communicative English when students are expected to communicate competently in English. English in polytechnics was designed to allow students to practise the language more and to be able to interact with the wider community. However, the assumptions imposed on the lecturers is a contributing factor in the implementation of the programmes which in the end have impact on graduates' quality. Hence, this study examined the challenges faced by English lecturers and content lecturers at polytechnics, teaching content in English and the collaboration between both English and subject lecturers.

\subsubsection{Teaching English at Polytechnic}

English has been the value-added subject taught in polytechnics. The importance of having competency in the language becomes one of the major concerns especially from the stakeholders. Therefore, polytechnics revise the syllabi used, to make them more inclined to meet the industries' needs. This resulted in the continuous changes made to the teaching and learning of English but lesser contact time. English for Specific Purposes was replaced by Communicative English as an approach used in English in polytechnics. The dilemma arises when in teaching and learning English, the students' core subjects in the teaching and learning because this would make learning English relevant to the students.

It is assumed that any qualified English lecturer should not have any problem in adapting her teaching strategies when conducting the lessons. This assumption may not be appropriate because, 
Communicative English teaching is not as easy as some may claim and may be more challenging when English is now used in teaching all technical lessons. ESP practices have always been complex and unpredictable but Communicative English approach contributes to the lecturers creating a more prominent gap between students' core disciplines and English. The lecturers are expected to be more flexible and diverse in teaching but at the same time, lecturers may settle for a more conforming teaching plan. The strengths of this approach are being sensitive to the learners' needs and their surroundings. The lecturers are expected to play multiple roles to ensure the approaches are always relevant to the students (Dudley-Evans and St.John, 2007).

The English lecturers in polytechnics had qualification in teaching English for General Purposes and with experience in teaching English in schools before they worked in this institution. Their background has helped to provide a general overview as lecturer respondents in this study. Five English lecturers were interviewed, and they were asked questions based on findings from students' questionnaires. These ESL (English as a Second Language) teachers were experts in teaching English for general purposes but were assigned to teaching technical English. Interview Extracts 1 gives background information of the lecturers' teaching experience. The Five English lecturers participated in this study and they were asked questions related to their experience in teaching English for Technical Purposes in the institution English lecturers were labelled as English 1 to English 5 in order to ensure their confidentiality.

\section{Interview Extracts 1}

English1: I have 30 years of teaching experience and I started teaching from primary school then have been teaching in polytechnic since 2000. There are differences in approaches and content in schools and polytechnics.

English2: I have been teaching in this institution for three years. Before working here, I taught at the community college.

English3: After a year of teaching at the community college, I was transferred to this polytechnic.

English4: Before teaching in polytechnic, I taught foreign students in Damansara.

English5: I have 20 years of teaching experience and I have been teaching in polytechnic for about seven years.

From these responses, it is noticed that the lecturers from this polytechnic have different backgrounds of experience in teaching English. Two of them, English lecturers 1 and 5, had years of experience teaching English in schools before they worked in the polytechnic context, as compared with the other three lecturers. However, all of the respondents did not differ much in their teaching years in polytechnics with experience teaching English for Technical Purposes (before ESP was taken over by Communicative English) for less than ten years. All of them were trained to teach General 
English (GE) but in a technical and vocational institution, such as this polytechnic, they were expected to teach English to technical students.

In most cases, the top decision makers such as the Director or the Head of Department believed that anybody with an English degree can teach ESP (Daoud, 2000; Fadhil, 2001). Unfortunately, without appropriate materials, adequate training and support, their teaching may not be as effective. This scenario is not only common in polytechnics, but a similar scenario is in other countries (MOE, 2012; $\mathrm{Wu}$ and Badger, 2009) and is listed as one of the challenges GE turned ESP lecturers have to face. Since ESP shared the same features and pedagogy as GE, most higher education institutions are confident that their English lecturers will be able to apply their knowledge in teaching English for General Purposes to cater to specific needs.

It is assumed that qualified English teachers should not have problems in adapting their teaching approach. However, there is no evidence in previous research that mentions qualified General English teachers as able to teach specific English without any training. The multiple roles expected from the lecturers indicate that the lecturers should be aware of teaching ESP extending beyond teaching (Dudley-Evans and St.John, 2007; Jordan, 1997). In General English class, the lecturers teach based on their perceptions of the students' needs but in ESP class, they need to know their students' needs in order to know what to teach (Gatehouse, 2001). They may have mastered all the fundamental knowledge and pedagogy in relation to language teaching but they still need proper training to teach new subjects. The English lecturer respondents did not state anything about them needing professional development but on-going learning will help to enhance their expertise thus make their teaching more relevant to the current needs.

English in technical institutions such as polytechnics, is generally, perceived by the management and content lecturers as a support subject to complement the technical components. Although the demands to have competency in this subject are overwhelming, the support of English programmes in polytechnics does not seem to match the demands. The demands that emerged from the nation's knowledge-based economy influence the trends of the workforce and higher education institutions such as polytechnics are expected to produce graduates who have competency in the language.

The DPE has adopted Communicative English as the approach that prioritized the students' learning needs, and it fits the aims to produce graduates who are skilful and ready to work. English becomes important because it is the language of science and technology and with competency in the language, students should be able to use their knowledge to help in learning their core subjects. Therefore, ESP is adopted because this approach is rooted in communication and learning needed by the students. It is thought that since ESP is seen as a branch of English Language Teaching, any welltrained English lecturers should not have any problem adapting to this approach in their lessons (Hutchinson and Waters, 2008). Nevertheless, the English lecturer participants provided different views about the current language programmes offered in this institution. They believed the current programmes were relevant for the students but did not allow rooms for students to practise their language.

English lecturer participants provided their views on the teaching strategies they had adopted, materials they used and the collaboration they had with the content lecturers. The interviews with the English lecturer participants showed they had different views and had adopted different strategies based on their beliefs. They too depended on the textbook or materials prepared for the lessons. Since 
they were not qualified ESP lecturers, these lecturers claimed they had to use their own strategies in teaching English at this institution. The responses from the interviews with English lecturers indicated that the lecturers contradicted pertaining to the language programmes and the current syllabus used was not sufficient to prepare the students to become work ready. Fadhil (2001) conducted a study on perception of ESP and believed that ESP was still a language affair and teachers made mistakes when they tried to become experts in both language and content.

Teaching English for Specific Purposes or ESP is more complex than it would appear. The nature of the whole programme which is based on learning-needs may contribute to the high demands expected by the relevant interest groups. The assumptions made about teaching English increase the challenges for the lecturers to perform effectively. The complexity of the teaching requires the lecturers to be agile and creative in utilizing this opportunity and they are expected to create teaching strategies adapted to suit their learners' demands.

ESP emphasizes making the teachers aware of their students' needs, but it is important for the ESP lecturers to know what this approach could offer before they even start teaching. New ESLturned-ESP lecturers should be aware of the demands of teaching which cannot be resolved with a textbook. With proper exposure and training, flexibility in ESP could give tremendous benefits to the students' learning. As Fadhil (2001) claimed, although the content can be alien to the lecturers, with some help from a technical dictionary and a good grasp of English, they will not have any problem in their teaching. It is common in ESP research to find that materials, expertise and status are challenges encountered by the lecturers (Hutchinson and Waters, 2008). These demands and expectations make this subject less attractive to teach.

\subsubsection{Teaching Content (ICT) in English}

The feedback from both set of participants provided insights at the micro-level perspective. ICT lecturers alleged that language competency in English did not influence students' academic performance. However, they did not deny learning the subjects in English could improve the students' competency in both fields, ICT and English.

I investigated lecturers' perceptions on the language shift and their strategies to adapt English in their ICT classrooms. The main reason for the language shift is to improve the students' English through using the language as a medium of instruction in class thus leading to a wider scope of employability. The knowledge and expertise of the ICT lecturers are recognized and their success in producing graduates who are competent in ICT is undeniable, but when they are asked to change their language of teaching from BM to English, this may trigger problems.

Interview Extracts 2 provides samples of the respondents based on their perception using English in their teaching. I have highlighted the important points made based on the implementation and strategies the ICT lecturers have opted. 


\section{Interview Extracts 2}

ICT 1: Bahasa Malaysia (BM) and English in class. BM for explanation because most of the students prefer BM. Even though, the programming language is in English, but explanation in BM.

ICT 2: Usually I use BM because when I use English, the students don't understand. We have to translate everything in $B M$ for example, quizzes, test papers etc.

ICT 3: For Semester 2, I have to teach in English. It is made compulsory. But for Semester 5, I tried to use English in the beginning of the semester but when the students don't understand, I use both languages.

ICT 4: One hundred percent BM. Because the original language is in BM. English is used in Semester 1 to Semester 3 classes so for Semester 5, I haven't translated my notes in English. In my other classes (Sem 4 and 5), I use both languages.

ICT 5: Main language in class is BM but sometimes, we have to use English because of the ICT subject, itself. The terms are more understandable in English but not all students can understand English.

The ICT lecturer participants used English and came out with strategies to ensure their learning was successful. The respondents agreed that they used BM and English in class and thought that adopting this strategy would help their students to understand better. They were worried that only using English might influence students' understanding of their teaching because they strongly perceived their students lacked competency in English. In Interview Extracts 2, the ICT lecturers' strategy to foster bilingualism in class was highly influenced by the students' requests, and their main purpose of teaching that was to achieve content meaning. To them, the success of the teaching was when their students understand the content.

Several observations in these classes were conducted to get further insights into the language usage in ICT classes. Observations were conducted for the purpose of discovering the percentage of English used, when it was used and why. I noticed English was used but BM was still the main medium of instructions. The ICT lecturers started their lessons in English but soon used BM throughout the lessons. BM was preferred for explanation and questions and answer sessions. In class, the lecturers and students were interacting in BM and English was used in a minimal way. English was only used for 'term' and 'jargon', but explanation was still in BM. Only ICT lecturer 2 claimed she chose translation methods and had to translate all the materials used in class. As an observer in an ICT classroom, I was impressed to see that the teaching materials such as students' notes and power point slides were in English but the ICT lecturers used BM for explanation. I predicted this strategy may cause difficulties for the students in adapting to the language switch but their reactions did not indicate any disorientation or confusion. Our classroom observations were further supported in Interview Extracts. I had asked the ICT lecturers' feedback pertaining to their language use in class and asked them to clarify the language they used in their teachings. 


\section{Interview Extracts 3}

ICT 1: Notes in BM but used slides in English. But I speak and explain in BM. I have to translate the notes in BM. The students understand better. Test paper and assessment are all in English. It was gazetted but the students can choose the language. Give only short answer.

ICT 2: Test paper is in both languages. But in Database system, I use one hundred percent English. It's easier for the students because the original words are in English. They become familiar with the subject and can understand better.

ICT 3: My notes are fully in English. I try to explain the content in English but if they still don't understand, I use BM. I try to train them to use one hundred percent English. I want them to get used to the language.

ICT 4: Notes are in English but test papers are in BM. Students get confused. We use both languages. We expose the students to both languages because in final exam, questions are in both languages.

ICT 5: Notes in English, teaching in BM. We use both languages. Power point slides are in English but explanation in BM. Students will not understand if the slides were presented and explained in English. Test papers are in both languages.

The semi-structured interviews with ICT lecturers confirmed that the lecturers used both languages, BM and English, not only as languages of instruction in the classroom but in the materials. I categorized the responses based on the functions and purposes of English in ICT materials. A significant number of materials were written in English because that was the original language in ICT. Original language here means the knowledge was produced and written in English and no translation was done. This was supported by ICT lecturer 2 in Interview Extracts. The respondent stated that using original language would help the students to understand better because they were exposed to it. Teaching materials help not only the students' learning but give confidence for the teachers. These materials include teaching notes and the students' references in class.

The ICT lecturers appeared to adopt similar strategies in managing the language change. They used BM for classroom communication and English for written materials. They felt students would comprehend the subjects better if they used BM. Their teachings stress the content without much interaction between lecturers and their students. The time constraints and demands of the syllabus limit the content lecturers in applying a more communicative teaching strategy that focuses on their students. The lecturers' strategies in coping with the language shift met the needs of the students. The interviews and observations reflected that the ICT classes were dependent on teachers and I noticed the similarities in ways they conducted their lessons. English is only evident in the written materials used in class and the medium of teaching is BM.

The language shift from BM to English in teaching content has been employed by the DPE as a strategy to improve students' English competency through learning content in English. The DPE 
aims to enhance students' second language skills when they receive extensive input in the target language. This agrees with Krashen's work on the issue of when students would best acquire language incidentally through a large amount of exposure to comprehensible second language input (Krashen, 2008). His premise rests on making sure that in a second language conversation meaning is achieved and mastering the rules should not become the priority. On the other hand, without adequate knowledge in the target language, students may not be competent in the language (Swain, 1988).

In this study, the aims of the DPE to produce students who are good in vocational purpose seem difficult to achieve if the subject lecturers emphasized content and avoided monitoring their students' linguistic skills. Their strategy to avoid dealing with the students' language may not be helpful in improving the language because without correct input, they will settle with having fluency but not accuracy.

As experts in ICT, the lecturers cannot avoid giving priority to the content and neglecting the language. One reason is they are not English lecturers, and their main task is to deliver content, not language. It is unrealistic to expect the content lecturers to respond to language deficits because they are inclined to centre their talk around academic content only (Lorenzo, 2007). Additionally, the lecturers are invested with non-academic workloads that are more demanding but helpful for their career advancement. Mohd and Mohd (2010) found the polytechnic lecturers claimed the difficulties they encountered to be efficient in teaching when the non-academic work disturbed their teaching tasks, but they agreed their experience in doing outside teaching jobs enriched their professional knowledge.

\subsubsection{Collaboration of English and ICT Lecturers}

Lecturers are the link the Department has with the students and they are the closest to the students. This makes them involved and aware of their students' needs and wants. Their perceptions pertaining to the English as a subject and English as the language for teaching the technical subjects helped to provide insights from a micro level perspective. The ICT and English lecturers gave their views based on their experience in teaching and learning both subjects, including their teaching strategies and classroom practices. In the beginning of this paper, I discussed and presented views from both subject lecturers based on their own disciplines. The interviews conducted with them showed the strengths of each subject lecturers and the obstacles they had to work with for their students to gain knowledge.

I needed to know their views on the subjects they taught, strategies they had adopted and beliefs that would help students to be better and more marketable graduates. Students in polytechnics learned English for specific purposes and they used this language in their ICT classes. The role of English in this institution evolves when the students have to learn their technical subjects in English. The DPE is confident that the language shift would help the students to learn their technical subjects because ICT is the language of ICT. The DPE's main objective is to make sure the students graduate with criteria that match industries' needs.

I have discussed both lecturers' views as their own and believed both subjects would work best if they cooperate and collaborate to maximise each potential. Interview Extracts 4 below shows the collaborative effort with English lecturers based on ICT lecturer participants' experience. 


\section{Interview Extracts 4}

ICT1: What our KJ (Ketua Jabatan) did, English lecturers help with our lab sheet. I heard this semester they'll do the same thing. But then, even when the English lecturers edited the work, the meanings again distorted. Once, when they corrected the grammar, the technical meanings were distorted. English lecturers need to be with content lecturers when they do the editing.

ICT2 : We have ICT staff who communicate in English.

ICT3: Not much. English lecturers helped to check the lab sheet. Helped editing and checking on grammar.

ICT4: Yes. IT lecturers did lab sheet, English lecturers help out with the editing. Usually by the end of semester, before making copies.

ICT5: We worked on lab sheet with JPA for editing. IT lecturers prepare the labsheet then hand to English. They did the editing.

The ICT lecturers claimed there was a collaborative effort between English lecturers. The expertise of English lecturers was needed for editing lab sheets when ICT lecturers needed to prepare teaching documentation in English. The English lecturers helped them with their grammar but unfortunately there were cases in which the English lecturers distorted the meaning. All ICT lecturers stated the collaborative effort was intended for correcting and editing the ICT materials but since English lecturers were not content experts, the technical lecturers needed to be with the language lecturers.

The English lecturers were interviewed and they were asked to share their experiences pertaining to the collaborative effort they had with ICT lecturers. Interview Extracts 5 below illustrated the feedback from English lecturer participants.

\section{Interview Extracts 5}

English 1: One and one, where by the content lecturers brought their RPPS, modules and we help them to vet through them. A lot of mistakes in their modules, them being content lecturers and help them to improve their modules. We go through their scheme of work and modules. We go department by department. We allocate certain lecturers. We also have grammar clinics with the lecturers. We find the lecturers are very happy with this. We have sort of an open day where the content lecturers can meet up with the English lecturers. One on one was good. I went to the IT department. I also went to the civil dept. They asked a lot of questions to understand the language better.

English 2: Is there any collaboration between content and language lecturers in PUO? No. 
English 3: Once. A short term one to one programme. A few lecturers were appointed to go to one of the dept (4-5 lecturers were assigned to go to one dept to revise the modules). It cannot be one way cooperation. We as English lecturers don't know basic things on technical, the lecturers need to be there to explain so that we can come out with correct note, grammatical, language. We checked, sat together with the lecturers. Asked them to explain to us about the syllabus. We checked page by page. It took us about a month. We went there twice. We managed to look through their syllabus.

English 4: Do you think the IT lecturers are aware of what being taught by English lecturers? I've no idea.

English 5: I think we are in our own world and IT lecturers in theirs. I think we have very little collaboration

Interview Extracts 5 with English lecturer participants provides information about the collaborative effort they had with the ICT lecturers, based on their experience as lecturers in this institution. The English lecturers claimed they had this one time, short-term programme that involved helping the technical lecturers with their modules. It was done on one to one basis. The English lecturer participants claimed during this programme, they revised the technical modules prepared earlier by the technical lecturers. They acknowledged the technical lecturers had to be there with them because they had to deal with technical text that was foreign to them. Without the technical lecturers, they were concerned that the revised version might distort the meaning. As well, English lecturer 1 mentioned 'grammar clinic' that was set up to assist content lecturers with English but it was another one-off programme initiated by the English Unit. This effort might not be successful because of demanding workload in this institution and lack of resources.

It is interesting to note that English lecturer 5 believed that both content and language lecturers were unaware of their counterparts' teachings and they belonged in their own world. He added that he felt there was not much collaboration between both of the subject lecturers. English lecturer 2 and 4 claimed there was no collaborative effort between subject and language lecturers. English lecturer 2, 4 and 5's perceptions contradicted with the claims made by English lecturer 1 and 3. The various perceptions from the English lecturers indicate uncertainties and not knowing the programmes run as their working institution. It is worrying if they continue to work on their own.

\subsection{DISCUSSION}

Implementing English in teaching content subjects, in this study, ICT needs thorough preparation in order to ensure its success. The Department of Polytechnic Education (DPE) stresses producing a high quality semi-professional workforce and determines to ensure they provide the best technical and vocational education to the students. The DPE believes learning technical and vocational subjects in English would give advantages to the students to be not only competent in technical skills but also have a grasp of good English for vocational and academic purposes. Even though English is perceived 
as an add-on subject in technical based institution, the students need the language as a catalyst to success. Lorenzo (2007) claimed English programmes in higher learning institutions need to consider linking ICT and English curricular agendas in such a way that L2 can be integrated within the subject matter content and consistently holding a dual focus in both classrooms. Therefore, it is important to maximise both expertise to develop more relevant modules for the students.

However, lack of awareness of the new policy among the lecturers affects the success of the programmes. ICT and English lecturers need to be well-informed and clear about the objectives of the top management, in this situation, Department of Polytechnic Education (DPE). Policy makers, the implementers and the students need clear direction in terms of implementation of language policy to avoid confusion (Gill, 2006). This is especially true of the lecturers who need to change their language from BM to English and apply it in significant aspects of teaching and learning in the field of science and technology. Both ICT and English lecturers should be clear about their department's direction to improve its graduates' competency in technical and language skills since they are the ones who will implement the plans. In reality, lecturers may be aware of the DPE and ministries' plans but might not be sure of to implement them.

\subsubsection{Lecturers as Front Liners}

Lecturers do not only have direct contact with the students but they are the link to ensure plans and policies inspired by the top management are successful. The DPE acknowledges their influences in teaching and learning, thus encourages the lecturers to further their studies and to attend professional development programmes. The DPE is determined to uplift the image of this institution through a highly qualified academic staff (DPE, 2009). Knowledgeable academic staff contributes in producing competent students but lack of skills in pedagogy practices and resources may be among the reasons that impede the success of any DPE programmes. Therefore, the Department may need to ensure that the lecturers comprehend of the objectives of any programmes and plans.

Many higher institutions, including the ones in Malaysia, have been practising top-down management, where upper management holds substantial responsibilities to ensure success (Tsai and Beverton, 2007). This top-down management structure determines the policies and plans to be executed by the lower levels, thought to be the best way to promote the necessary equilibrium and efficiency of complex systems composed of numerous individuals and units (Milgrom and Robert,1992) cited in (Tsai and Beverton, 2007). In this centralised management system, the leaders should make sure that their subordinates are aware of the mission and vision and motivate them to work towards making the plans work effectively.

The feedback given by the lecturer respondents reflected that they were not truly aware of new policies and planed inspired by the top management. Arguably, the leaders have prepared memoranda and gazetted notices that do not reach their subordinates, effectively contributing to lack of implementation. English and ICT lecturers have the pedagogy knowledge and experience in teaching their subject but not certain of ways to implement it. The dual dilemma of English lecturers who have the teaching knowledge but are not trained to adapt their teaching to new approaches, and the dilemma of ICT lecturers who are content experts but have to change their medium of instruction in 
class from BM to English, presents an implementation problem. These lecturers each need training and professional development to make sure they are motivated and involved in running the top management's plans successfully. Although, as Handcome (1990) has suggested, "the best content teaching is the best language teaching", without proper implementation both the language and content can be impaired (Lorenzo, 2007).

Subject lecturer participants claimed collaborative efforts between themselves and English lecturers were very superficial. English lecturers helped to edit, and proof read the ICT syllabus prepared by the lecturers to make it more comprehensible. However, there did not appear to be any contribution from ICT lecturers in developing the English modules. Unfortunately, both disciplines were deprived from receiving input from the subject experts. I believe both lecturers need proper training and exposure on how to negotiate and harmonize their expertise and imply it to the benefits of both subjects.

\subsubsection{Harmonising the Conflicts}

This study discovered that both ICT and English lecturers acknowledged the role of English in ICT learning and for the students' future. The ICT lecturers used English for reading technical materials in class but maintained the medium of instruction in BM. The ICT lecturers' strategies might meet the needs of the students but might conflict with the expectation of the top management and industries; students need more exposure and practice using English in learning content. It actually conflicts with the DPE's intention to produce employable graduates who are competent in the language for academic and workplace purposes.

The study also revealed the limited collaboration effort between English and ICT lecturers. There were programmes conducted to maximise their teamwork but most of the programmes was a one-off thing. The reasons might be related to heavy academic and non-academic workload assigned to both subject lecturers. Moreover, both lecturers were not well informed of things happening at their workplaces and affected their performance in class. Non-academic workload in polytechnics is important, as it is one of the criteria needed for promotion. The dilemma and incapability to manage multiple workloads might contribute to them not knowing the expectation from industries, the DPE including their own colleagues. The gaps of needs and expectation of the stakeholders might be the reasons for the ineffectiveness of the education programmes.

Since the DPE was very flexible pertaining to the strategies to implement English, the lecturers initiated their own approach to use the language in class. The functional bilingualism practice in polytechnics is situated within the classroom context. Based on the classroom observations in ICT classrooms, English is used for teaching materials and students' references. The results from the qualitative data showed the strong inclination the DPE has towards bilingualism in polytechnics. However, to ensure this strategy would help to achieve DPE's target objective to produce graduates who have English competency for workplace purposes, the Department should provide regular support for the lecturers.

The language shift might cause hardship to the ICT lecturers who received training in Bahasa Malaysia (BM) and personally were not good in the language. Using English in class would not only improve the students' language competency, but if the ICT lecturers' language too. However, if the 
language is only used in teaching materials and reading text, the Department's target objective might be harder to achieve. The challenges, these lecturers have to endure would be less tormenting if they have support to build up their confidence and able to master the language in class. Then, when the ICT lecturers' English has improved, they should be able to encourage their students to use the language instead of maintaining communication and explanation in BM.

If the DPE insists on encouraging bilingualism in teaching technical subjects, it needs to make sure the lecturers and students have the support and they are aware of the strategies to adopt. The ICT lecturers should know the objectives behind this language shift. There should be consistent monitoring not only on the ICT syllabus, but also on the language use in class. ICT is indeed in English and the students would learn better if they were exposed to the original terms. However, the demands of industries go beyond knowing the technical or hard skills (Kelan, 2008). They expect the students to graduate with soft skills and be ready to work. The increasing needs of industries might be diverse but the data from the industry participants showed they acknowledged the importance of English at the workplace.

\subsection{FUTURE RECOMMENDATION}

The findings in this study showed the lecturers as the front lines should be given support and professional development to establish a better link between technical and language lecturers. The support could include preparing programmes that could oriented new lecturers to the system and could expose senior lecturers to the new approaches. The directions planned by the Department of Polytechnic Education should be observed by staff from all levels through better education.

The experts of both technical and language worlds could be strengthened. The interviews with ICT and English lecturers indicated both lecturers worked in isolation even though there were attempts for collaboration. Collaboration inter-department can be explored more in terms of teaching and learning activities, students' activities and assessments which unfortunately still lacking in the system.

The DPE appears confident that its lecturers are able to adapt any set of policies with minimal support and supervision. Nevertheless, the findings indicated differently. There should be better collaborative effort between two groups of experts. The ICT lecturers know about content and the English lecturers are good in language and language teaching. In addition to that, heavy nonacademic and management workload and high expectation placed on both lecturers might contribute to them not being able to allocate their time and energy for better teaching.

\subsection{CONCLUSION}

Lecturers are the central element in the polytechnic education system, holding various responsibilities that are pertinent to ensure the education system runs smoothly. The challenge in teaching and 
learning English is educating the workforce to be flexible and able to adapt the teaching approaches as designed by department. The continuous revamp done to the syllabus might not be effective if the lecturers who implement are not certain of the expected outcome. They are committed to connecting their work performance, innovative abilities, integrate new ideas into their own practice, as well as having important influence on students' achievement and attitudes (Tsui and Cheng, 1999). The lecturers' backgrounds influence their interpretations of classroom situations and students' behaviour and pedagogical decisions (Noordhoff and Kleinfeld, 1993) as cited in (Smith, 2000).Teachers are actively influential in all classes regardless of the subjects, so it is important for the department to ensure their academic staff has the capability to deliver high quality teaching. The lecturers' contributions should be acknowledged because their identities, cultures and experiences help shape their view of teaching and practice. Multiple and on-going support from the top management to the lecturers would contribute to ensure further success in the students' education.

\section{REFERENCES}

Bennet, N., Dunne, E., and Carre, C. 2000. Skills Development in Higher Education and Employement. Philadelphia: SHRE and Open University Press.

Daoud, M. 2000. LSP in North Africa: Status, Problems and, Challenges. Annual Review of Applied Linguistics. 20: 77-96.

DPE. 2009. Hala Tuju Transformasi Politeknik Ke Arasa Kelestarian Penghasilan Modal Insan Negara (Vol. 1). Selangor: MoHE.

DPE. 2011. The Link. The Link, Jan-June 2011.

DPE. 2012. Peningkatan Penguasaan Bahasa Inggeris Bagi Pensyarah Politeknik Kementerian Pengajian Tinggi Malaysia. Putrajaya: DPE.

Dudley-Evans, T., and St. John, M. J. 2007. Developments in English for Specific Purposes: A MultiDisciplinary Approach. Cambridge University Press.

Fadhil, H. A. Y. Mansor. 2001. A Case of an Extra-Sensitive Perception of ESP. GEMA Online Journal of Language Studies. 1(1).

Fraenkel, J. R., and Wallen, N. E. 2000. How to Design and Evaluate Research in Education. McGrawHill Higher Education.

Gatehouse, K. 2001. Key Issues in English for Specific Purposes (ESP) Curriculum Development. The Internet TESL Journal. 7(10).

Gill, S. K. 2005. Language Policy in Malaysia: Reversing Direction. Language Policy. 4(3): 241-260.

Graduates Unemployable Due to Poor English. (2010, April 1). The Staronline. Retrieved from http://thestar.com.my/metro/story.asp?file=/2010/4/1/north/5963162andsec=north.

Hutchinson, T., and Waters, A. 2008. English for Specific Purposes: A Learning-centred Approach. Cambridge University Press.

Johnson, B., and Christensen, L.2008. Education Research: Quantitative, Qualitative, and Mixed Approaches. Sage Publications Inc. 
Jordan, R. R. 1997. English for Academic Purposes: A Guide and Resource Book for Teachers. Cambridge University Press

Kelan, E. K. 2008. Emotions in a Rational Profession: The Gendering of Skills in ICT Work. Gender, Work and Organization, 15(1): 49-71. Doi: 10.1111/j.1468-0432.2007.00355.x

Krashen, S. D. 2008. Language Education : Past, Present and Future. RELC Journal. 39(2): 178-187.

Lorenzo, F.2007. An Analytical Framework of Language Integration in L2 Content-based Courses: The European Dimension. Language and Education. 21(6): 502-514.

Naidoo, R., and Jamieson, I. 2005. Knowledge in the Marketplace: The Global Commodification of Teaching and Learning in Higher Education.

MOE. 2012. Pelan Strategik Interim Kementerian Pelajaran Malaysia 2011-2020. Putrajaya.

Mohd Ali Jasmi, and Mohd Amin Zakaria. 2010. Lecturers Perceptions on Workload, The Impact Towards The Effectiveness of the Teaching and Learning Process in Polytechnic. Paper Presented at the 1st UPI International Conference on Technical anda Vocational Education and Training, Bandung, Indonesia.

Mohd Najib Tun Abdul Razak. 2010. 10th Malaysia Plan. from

The Economic Planning Unit, PM Dept, Malaysia http://www.epu.gov.my/html/themes/epu/html/RMKE10/rmkel0_english.html

Smith, R. W. 2000. The Influence of Teacher Background on the Inclusion of Multicultural Education: A Case Study of Two Contrasts. The Urban Review. 32(2): 155-176. Doi: 10.1023/a:1005133815768.

Swain, M. 1988. Manipulating and Complementing Content Teaching to Maximize Second Language Learning. TESL Canada Journal. 6(1): 68-83.

Tilak, J. B. G. (Ed.). 2002. Vocational Education and Training in Asia. Kluwer Academic Publishers

Tsai, Y., and Beverton, S. 2007. Top-down Management: An Effective Tool in Higher Education? International Journal of Educational Management. 21(1): 6-16.

Wan Noor Wan Kamaruddin, and Mohammed Sani Ibrahim. 2010. Enhancing Lecturer Competency of Malaysian Polytechnic Technical Lecturers: A Discrepancy Analysis. Proceedings of the 1st UPI International Conference on Technical and Vocational Education and Training. 1: 283-290.

Wu, H., and Badger, R. G. 2009. In a Strange and Uncharted Land: ESP Teachers' Strategies for Dealing with Unpredicated Problems in Subject Knowledge During Class. ScienceDirect. 28: 1932.

Yee, A. S. V., and Liew, J. S. 2011. Comparative Studies on Key Indicators Used in Performance Measurement System of Polytechnics' Academic Staff. Paper Presented at the 2nd International Conference on Business and Economic Research Proceeding. 